\title{
El ejercicio de la acción y la búsqueda a la tutela judicial efectiva: una visión constitucional en España y Brasil
}

\author{
Adriano Moura da Fonseca Pinto ${ }^{1}$
}

\begin{abstract}
Resumen
El ejercicio del derecho de acción se relaciona tradicionalmente con el acceso a la justicia, inicialmente con un sesgo más formalista y limitado con el derecho a obtener una respuesta judicial cognitiva, incluso en sus espacios recursivos. A medida que pasan los años y, formateando los estados de derecho y sus constituciones, el ejercicio formal de la acción va incorporando derechos más centrados en la efectividad de la disposición judicial, que se asocia particularmente a las órdenes constitucionales, por regla general. Así, este texto aporta una visión constitucional respecto al ejercicio de la acción y la jurisdicción en España y Brasil, con énfasis en doctrinas convergentes la idea de tutela judicial efectiva.
\end{abstract}

Palabras-clave: Acción; Tutela judicial efectiva; España; Brasil.

\begin{abstract}
The exercise of the right of action is traditionally related to access to justice, initially with a more formalist and limited with the right to obtain a cognitive judicial response, even in the appeal spaces. As the years pass with the states of law and their constitutions, the formal exercise of the action are incorporating rights more focused on the effectiveness of the judicial provision, which is particularly associated with constitutional commands, as a rule. This text brings a constitutional view regarding the exercise of action and jurisdiction in Spain and Brazil, with emphasis on convergent doctrines the idea of effective judicial protection.
\end{abstract}

Keywords: Action; Effective judicial protection; Spain; Brazil.

\footnotetext{
${ }^{1}$ Profesor y Coordinador Adjunto del Programa de Posgrado en Derecho de la Universidad Estácio de Sá en Rio de Janeiro - Brasil. Posdoctorando en Derecho - Facultad de Derecho y Criminología de la Universidad Autónoma de Nuevo León - México. Mestrando del Programa de Posgrado en Justiça Administrativa da Universidade Federal Fluminense. Membro do Comité Científico da Conferencia Universitaria para el Estudio de La Mediación y el Conflicto - CUEMYC (España). Consultor Internacional de la FACPYA - Universidad Autónoma de Nuevo León (México).. Membro do Observatório de Política Pública, Direito e Proteção Social e fundador do Observatório de Mediação e da Arbitragem, ambos do PPGD da Universidade Estácio. de Sá. Vice Coordinador del Comitê de Ética em Pesquisa da Universidade Estácio de Sá. Membro da Comissão de Estudos em Processo Civil da OABRJ.
} 
Para tratar del ejercicio de la acción y la búsqueda del derecho a la tutela judicial efectiva partimos de una consideración primera como es la de que el estudio de la Acción se ha desarrollado como parte integrante de un análisis de los elementos tradicionalmente tratados por la doctrina como son Jurisdicción y Proceso y el concepto de Estado de Derecho.

A la vez que los Estados se cualifican como de Derecho, comienzan a basar su existencia, legitimidad y actuación en base a la ley moldeando sus Constituciones, el estudio de la Acción, también, va pasando de las manos esencialmente de los particulares y sus derechos materiales hacia un derecho más generalista, de carácter definido como público, autónomo del derecho privado y su existencia, aunque la transición de la autonomía haya pasado por las ideas de concreción antes de llegar al abstractismo que se sostiene, si bien con variables, en la actualidad.

Tal cambio, del ámbito predominantemente privado, tiene sus razones jurídicas y lógicas, pautadas principalmente en el binomio Igualdad- Legalidad, imprescindible para que el Derecho en cuanto ley pudiera ser pensado, redactado, validado y aplicado ante todos en el ámbito del movimiento Liberal que se instituía contra las seculares arbitrariedades del Estado y de la Iglesia.

Por la Igualdad, todos, como en un pase de magia, quedaban en una situación fáctica y jurídica de homogeneidad, aptos para ser tratados en el mundo privado o público de la misma forma. Así, al aplicar la Legalidad en el entorno de los Estados de Derecho, jueces y tribunales sólo deletreaban lo que fue legislado y, como mucho, interpretado con los criterios ya conocidos del Positivismo Jurídico clásico.

Siendo todos iguales ante la ley, el ejercicio de derechos, aquí en el caso, el derecho de acción también fue, en cierto modo y por tiempo, garantizado por la letra fría de la legislación positivada. La separación del derecho material ya se había producido. Todos ahora eran iguales ante la ley que regula, entre otros derechos, el derecho de acción, de modo que la acción sale de escena, dando lugar a los dos otros elementos esenciales para el Derecho Procesal: Jurisdicción y Proceso como garantía de los justiciables. ${ }^{2}$

Es más, con la primacía del propio Estado sobre el control de la actuación de sus jueces y tribunales, el ejercicio de la Jurisdicción comenzó a ser el centro de las atenciones de la doctrina, así como el Proceso, que se acaba convirtiendo en el instrumento de realización del Derecho a través de los jueces y tribunales en base al Derecho legislado. Se concentra con la Jurisdicción el centro de las atenciones para, posteriormente, centrarse en la Acción y, finalmente, llegar al Proceso, convirtiéndose éste en el gran instrumento de transformación que necesita adecuarse para que funcione como instrumento del Estado.

Al permitirse tal cambio, el Estado de Derecho centraliza en la Jurisdicción el acceso a la Justicia, partiendo de una conceptualización y una caracterización que tiene como referencia

2 ALCALA ZAMORA Y CASTILLO, N. Proceso, Autocomposición y Autodefensa, México, 1991, p. 231. 
la actuación de jueces y tribunales. ${ }^{3}$ Se trata de una verdadera incorporación del acceso a la Justicia por parte del Estado, alejándose completamente de la idea de accesibilidad de la Justicia por el particular y para el particular, con sus características, realidades, peculiaridades, y que evoluciona hacia una idea de acceso a la Justicia con la forma y contenido propuesto por los Estados.

Junto con los particulares, ahora también el nuevo Estado, debe ser y está siendo una referencia para el acceso a la Justicia para jueces y tribunales. En otras palabras, es la Acción, delineada por la Jurisdicción y por el Proceso, la protagonista, y no en el ejercicio en sí, a diferencia de lo que se había diseñado, por ejemplo, en el período romano.

Como ya se ha mencionado, existía una cierta lógica (que incluso se puede criticar actualmente), de desplazar el discurso de pensamiento, legislación y actuación del Derecho por parte de los jueces y tribunales hacia el ámbito de la Jurisdicción y los límites en los que se produce en el proceso. La lógica, (aunque falseada por la validez simple en la norma positivista), es la premisa de que todos serían iguales ante la ley, pudiendo, por tanto, recibir un tratamiento genérico por parte de la ley. Tenía un sentido orgánico, pero carente de materialidad fáctica en la micro aplicación de la accesibilidad por parte de los ciudadanos hasta que obtuvieran su Justicia, bien fuera una simple respuesta, bien fuera la realización material de la pretensión en sí.

Así, la idea de tratar inicialmente la Acción en Roma de forma separada de la Jurisdicción y del Proceso es comprensible y de cualquier forma incluso culpablemente justificable. Por ello, la Jurisdicción y del Proceso se configuran como los elementos decisivos para que sea factible la consecución de la Justicia por parte de jueces y tribunales, a partir de la segunda mitad del siglo XIX, actitud que perdura como el hilo conductor de los estudios y enseñanzas del Derecho Procesal hasta la actualidad sin muchos cuestionamientos, insistimos, y con raras excepciones por el fracaso del resultado final.

Un simple análisis del contenido de los manuales y obras clásicas de Derecho Procesal, especialmente en el campo de la Teoría General del Proceso pone de manifiesto con suficiente rigor, el orden y la dinámica del enfoque de la ciencia procesal: "Jurisdicción, acción y proceso". ${ }^{4}$ El estudio del Derecho ¿inicia con la búsqueda de la Justicia por parte del Estado que juzga y no con el ciudadano que ejerce la búsqueda de la Justicia? ¿Es correcto? En el presente texto entendemos que no.

La segunda consideración (2) se refiere a algunas consecuencias que se producen por el fortalecimiento de la posición tradicional de la doctrina, ley y jurisprudencia de emprender el estudio de la búsqueda de la Justicia partiendo de la idea de justificación de la Jurisdicción,

\footnotetext{
${ }^{3}$ PedRAZ PENAlVA, E. Derecho Procesal Penal. Tomo I. Princíios de Derecho Procesal Penal, Ed. Colex, Madrid, 2000, p, 33.

${ }^{4}$ Ibidem, p. 37.
} 
para después hablar de la Acción y, por último, argumentar acerca del Proceso. ${ }^{5}$ La primera consecuencia (2.1) es que tal posición, principalmente reforzada a lo largo del último siglo, acaba insertando la Justicia en los límites del Proceso y de la Jurisdicción, principalmente en sus aspectos más formales ${ }^{6}$, dejando la actuación de las partes interesadas, en otras palabras, la Acción, a merced de lo que es lícito (legal y constitucionalmente hablando), para llevar a cabo el Proceso con la bendición de la Jurisdicción, en los términos de la legalidad positivada y validada, llena de argumentos técnicos, pero sin tener en cuenta que todo esto sucede en medio de la sociedad X el Estado. Aquí se pone de manifiesto un falso equilibrio y una rectitud basada únicamente en la previsibilidad de la ley y en la consecuente limitación de su acción o actuación.

Se trata, según hemos presentado, de una inversión de valores para pensar, legislar y aplicar las herramientas facilitadas a los ciudadanos en la búsqueda de la Justicia. En un marco democrático, se busca con ahínco y preocupación lo justo (que puede llegar a rozar la utopía en ocasiones), y los parámetros de justificación están necesariamente ligados a los valores extrínsecos (extraprocesales) a la acción, la defensa y el juicio, vinculados no sólo a lo que uno se imagina de la intervención estatal en el sector privado, sino también a los medios propicios para tal realización en la práctica, tipificados en la legislación procesal como posibles actos de las partes, abogados, procuradores, jueces.

Tanto unos como otros valores son explícita e históricamente vulnerables a los elementos que poco o nada tienen que ver con las personas y sus acciones que buscan la prevención o reparación del orden de su derecho material, pero que en gran medida afectan social, económica y políticamente sus vidas. Eso constituye el efecto pero no la causa. Los presupuestos públicos, la gestión de los recursos personales y materiales, la realidad sociocultural de las personas, son sólo algunos ejemplos de lo que podríamos considerar valores o factores extraprocesales que ejercen influencia en la mayor o menor accesibilidad a la Justicia de jueces y tribunales. ${ }^{7}$

Los valores o los factores fuera del proceso pueden considerarse como los que están insertados en la mayor o menor limitación de las posibilidades jurídicas que se derivan del ejercicio de la acción, de la respuesta de la Jurisdicción, de las personas calificadas como acusadas, de los funcionarios de la justicia, como los expertos, etc. Abarcan, en efecto, la suma de las posibilidades de los más diversos actos procesales que se pueden producir desde la distribución de la petición de la acción, comenzando por el rito o el procedimiento específico hasta el pronunciamiento de la ley y, si es necesario, también la participación de los recursos necesarios para la ejecución forzada del derecho material, cuando no se cumple voluntariamente.

\footnotetext{
${ }^{5}$ Ibidem, p. 37.

${ }^{6}$ MONTERO AROCA, J., Introducción al Derecho Procesal, Ed. Tecnos, Madrid, 1976, p. 19.

${ }^{7}$ CICHOCKI NETO, J. op, cit. p. 99. 
Son los valores o los factores que pueden limitar el ejercicio de la acción, haciendo que las personas naturales o jurídicas consigan ejercer (recibir) el derecho a la tutela judicial efectiva, previsto en las Constituciones de España (art. 24.1) y Brasil (5', XXXV), respectivamente. Es así, por lo tanto, que en este Capítulo III, intentaremos medir la efectividad del mandato constitucional del Derecho Fundamental de acceso a la Justicia, en el sentido de que se intenta garantizar a los sujetos involucrados en el proceso judicial, toda la legislación procesal infraconstitucional y constitucional existente, incluyendo ahí, el pilar de los Principios Constitucionales, en particular los que sostienen los derechos fundamentales, ya sean ellos derechos fundamentales materiales o procesales, como es el caso de la Acción, tal y como defendemos.

Mediante la Acción, ${ }^{8}$ los ciudadanos obtienen el contenido íntegro de la tutela judicial efectiva en los casos llevados a los jueces y tribunales en España y Brasil. No deberíamos, como ya hemos indicado anteriormente, partir de la Jurisdicción sino de la Acción como un derecho que, una vez ejercido, genera la actuación de la Jurisdicción en el ámbito del Proceso. Se afirma que por el impulso inicial de la Acción, durante todo el tiempo que se requiere para su ejercicio, el contenido de la tutela judicial efectiva se respeta por los jueces y tribunales, generando así los pronunciamientos judiciales capaces de hacer que el Proceso Judicial sea legal y constitucional.

Puesto que los jueces y tribunales ejercen su autoridad estatal en la conducción de los procesos judiciales, mucho de lo que se considera contenido en la tutela judicial efectiva pasa, sin duda, por las manos de los jueces. La relevancia que se da a la Jurisdicción a partir de fuentes distintas del pacto constitucional, puede desembocar en que el mandato mayor de acceso a la Justicia no se cumpla.

Son, por lo tanto, las personas y el Estado insertados formalmente en los procesos judiciales, o simplemente afectados por ellos, como por ejemplo en los casos de jurisdicción propiamente constitucional, cuando la actuación del Tribunal Constitucional o del Supremo Tribunal Federal, o incluso en las hipótesis de las llamadas acciones colectivas, aquéllas en que el pronunciamiento judicial afecta a un determinado grupo de personas, cuando no sea derecho difuso como, por ejemplo, el medio ambiente.

La segunda consecuencia (2.2) es que, al aplicar la Jurisdicción, por regla general jueces y tribunales lo hacen en según la doctrina positivista clásica, dando protagonismo a los códigos y a otras normas procesales infraconstitucionales, sin que haya, salvo excepciones más recientes, un gran apego a la utilización de la normativa procesal de las Constituciones, volviendo aquí al escenario de los "Constitucionalismos" (apuntado en el Capítulo I y sobre lo que volveremos principalmente en el Capítulo IV).

\footnotetext{
${ }^{8}$ Luiz Guilherme Marinoni sostiene la posición aquí también defendida y que será mejor analizada con respecto al contenido de la tutela judicial efectiva, por la cual: "la acción no se resume al acto que invoca la jurisdicción. No es un acto solitario, como si el derecho de acción pudiera limitarse a un requerimiento de tutela jurisdiccional."
} 
España y Brasil experimentan situaciones jurídicas con un alto grado de similitud ante el tema de la accesibilidad a la Justicia a través de los jueces y tribunales, a favor del mayor mandato de la tutela judicial efectiva, en base a sus respectivas Constituciones garantistas, llena de derechos fundamentales, incluso el derecho fundamental de acción (a favor de la tutela judicial efectiva), pero con su ejercicio, en la práctica regido principalmente por jueces y tribunales que no se separan de las respectivas Constituciones, mucho más que los jueces y tribunales provenientes de la separación de poderes de la versión más antecedente del Estado de Derecho.

El hecho es que la Jurisdicción, ya sea por factores internos o externos a lo que sucede en las líneas del Proceso, dudó en aplicar, como norma, las respectivas Constituciones más allá del formalismo jerárquico positivista, y limitando su eficacia, ya sea en el ámbito político, ya sea en el ámbito de los derechos materiales fundamentales, con justificaciones dudosas.

Pero ¿cómo se producen estas situaciones? Se producen en el ámbito tanto externo como interno a los procesos, como se ha dicho (factores o valores extraprocesales y intraprocesales), dado que tanto en un caso como en el otro, el derecho de Acción se ve afectado, sobre todo reducido y, con él, las Constituciones y sus Principios prometedores, primero en el ámbito del derecho procesal y, seguidamente (ya que depende de este), en el ámbito del derecho material de las personas. Éstas tienen grandes dificultades para llevar a cabo la acción de declarar, constituir u obtener la condena a la vulneración de sus derechos; también para el pago, a través de la acción ya en fase de ejecución de las obligaciones contenidas en los pronunciamientos judiciales (pagar una cierta cantidad, hacer/no hacer y entregar bienes); también para los títulos ejecutivos extrajudiciales, ya que es similar a la tutela directiva.

Por ello, resulta necesario analizar la tutela judicial efectiva propiamente dicha, teniendo en cuenta su tipicidad legal, su respectiva naturaleza jurídica, su concepto y su contenido formal y material en España y en Brasil. En todos los campos mencionados anteriormente, nuestro estudio trata de acentuar el tema específico, indagando sobre la legislación, la doctrina y la jurisprudencia, elementos característicos e indicadores de la dirección que se tiene, en la teoría y práctica, el mencionado tema en particular.

\section{PREMISAS DEL DERECHO A LA TUTELA JUDICIAL EFECTIVA EN ESPAÑA Y BRASIL}

Se observa que países como España y Brasil, cada uno con capítulos propios de su historia más que secular, tuvieron en la segunda mitad del siglo XX significativos cambios de régimen político y secuencialmente jurídico con sus respectivas Constituciones de 1978 y 1988, ambas que reflejan, dentro de sus particularidades, el salto que se pretendía en el ámbito del Derecho, principalmente en lo que se refiere a la estructuración, organización y funcionamiento de la máquina judicial a favor del acceso a la Justicia como un derecho fundamental. 
Tras las mencionadas Constituciones, España y Brasil pasaron por un intenso cambio legislativo infraconstitucional, en particular el derecho procesal, a fin de que sus respectivas Constituciones alcanzaran la mesa de jueces y tribunales, teniendo un acceso cada vez más cuantitativo y cualitativo de respuestas judiciales a favor de la Justicia. Este hecho se produjo, como consecuencia lógica y natural de cambio constitucional, obviamente, no sólo por la influencia del campo político de la labor legislativa del Derecho, sino también de modo significativo por el Derecho resultante del Tribunal Constitucional y del Supremo Tribunal Federal, por dictar, a lo largo de las décadas pasadas, no sólo los contornos de la tutela judicial efectiva en cada uno de los países, sino también el modo de tutela (protección) de todos los demás derechos fundamentales.

La tutela (protección) de los derechos fundamentales en general en España y Brasil se ha ido produciendo con mayor proximidad que distancia, sobre todo en el campo del fundamento constitucional de las últimas decisiones de sus tribunales. Aunque esto haya ocurrido con diferentes instrumentos procesales, con la primacía del fundamento de las respectivas Constituciones y la aplicación normativa a los Principios también es notorio sea con Post-Positivismo, el Neoconstitucionalismo o incluso, en el caso de Brasil, de un Nuevo Constitucionalismo Latinoamericano.

\section{LA TIPICIDAD CONSTITUCIONAL DA LA TUTELA JUDICIAL EFECTIVA: POSICIONES DOCTRINALES EN ESPAÑA Y EN BRASIL}

El art. 24.1 $\mathrm{CE}^{9}$ y el art. 5 ${ }^{\circ}, \mathrm{XXX}$ de la $\mathrm{CRFB}^{10}$ incluyen las disposiciones constitucionales del derecho fundamental a buscar la Justicia ${ }^{11}$ a través del ejercicio del derecho de acción, mediante la provocación a jueces y tribunales. Estamos ante un derecho fundamental procesal, que sirve, incluso, como medio de realización de los demás derechos fundamentales, cuando no se entreguen naturalmente a los respectivos titulares. ${ }^{12}$

En efecto, las dos disposiciones mencionadas, a pesar de que se configuren como exponentes referenciales del derecho al fundamental Acceso a la Justicia a través de los jueces y tribunales en los respectivos países, no consiguen por su textualidad, presentar un contenido completo (instituciones e institutos procesales) que reflejen el Derecho dictado por las

\footnotetext{
${ }^{9}$ Art. 24.1 CE .Todas las personas tienen derecho a obtener la tutela efectiva de los jueces y tribunales en el ejercicio de sus derechos e intereses legítimos, sin que en ningún caso, pueda producirse indefensión.

${ }^{10}$ Art. 5. CRFB. Todos son iguales ante la ley, sin distinción de cualquier naturaleza, garantizándose a los brasileños y a los extranjeros residentes en el País la inviolabilidad del derecho a la vida, a la libertad, a la igualdad, a la seguridad y a la propiedad, en los términos siguientes: [...] XXXV - la ley no excluirá de la apreciación del poder Judicial lesión o amenaza al derecho.

${ }^{11}$ MONTERO AROCA, J., GÓMES COLOMER, J.L., BARONA VILAR, S., Derecho Jurisdiccional I. Parte General, Ed.Tirant Lo Blanch, Valencia, 2007, p. 220.
} 
decisiones del Poder Judicial. Tanto en el ámbito constitucional, como infraconstitucional, se expanden en las propias disposiciones, inherentes a los institutos de derecho procesal para el acceso a la acción, a la jurisdicción y al proceso.

En el caso, de España, el art. 24.1 CE se combina inicialmente con los artículos $117 \mathrm{CE}$ hasta $127 \mathrm{CE}$, que serán oportunamente abordados en el tratamiento de los institutos de la acción, jurisdicción y proceso correspondientes. Además de estas disposiciones, que reflejan la actividad del Poder Judicial como un todo, no se puede dejar de mencionar los artículos 159 hasta 165 CE relativos a la actuación del Tribunal Constitucional. ${ }^{13}$

Brasil cuenta con una situación similar y más agravada, puesto que no se organizó en el ámbito constitucional, de modo amplio, lo que viene a ser el contenido de la tutela judicial efectiva. A modo de aclaración, la expresión reiteradamente utilizada para referirse a la "tutela judicial efectiva" en el país es de carácter semántico mucho más amplio; "acceso a la Justicia" o "inapartabilidad ${ }^{14}$ de la jurisdicción". Tal denominación, a pesar de que permita un abanico quizá más extensivo de elementos que puedan influir en el resultado de la Acción, Jurisdicción y Proceso, acaba dificultando el tratamiento más específico y, también más efectivo.

Así, superada la diferenciación anterior, de modo equivalente al texto constitucional español, la Constitucion de la República Federativa de Brasil posee en diversas otras disposiciones normas y principios que se refieren a la acción, jurisdicción y proceso a favor de una tutela judicial efectiva. Siguiendo un orden meramente cronológico, es en el propio art. $5^{\circ}$ CRFB, en su párrafo y diversos incisos, los que corresponden a los derechos fundamentales a la acción, jurisdicción y proceso. ${ }^{15} \mathrm{El}$ citado art. $5^{\circ} \mathrm{CRFB}$ abre en el texto constitucional el

\footnotetext{
${ }^{13}$ Se ha optado aquí por no citar todos los artículos de la CE de una sola vez, debido a la extensión y amplitud de los temas tratados. De acuerdo con la aparición temática, los mismos serán mencionados y descritos a lo largo de nuestra investigación. Lo mismo vale para las disposiciones correspondientes de la CRFB de Brasil.

${ }^{14}$ En este punto, hacemos expresa referencia al principio de "inafastabilidade", que es traducido como principio de "inapartabilidad de la jurisdicción", es decir, que la jurisdicción no puede apartarse o ser apartada de la función de juzgar.

${ }^{15}$ Art. $5^{\circ}$ (párrafo) CRFB. Todos son iguales ante la ley, sin distinción de cualquier naturaleza, garantizándose a los brasileños y a los extranjeros residentes en el País la inviolabilidad del derecho a la vida, a la libertad, a la igualdad, a la seguridad y a la propiedad, en los términos siguientes: [...] XXXV - la ley no excluirá de la apreciación del poder Judicial la lesión o la amenaza al derecho;[...] LIII - nadie será procesado ni condenado si no por la autoridad competente; LIV - nadie será privado de la libertad o de sus bienes sin el debido proceso legal; LV - a los litigantes, en el proceso judicial o administrativo, y a los acusados en general se les asegura el contradictorio y la amplia defensa, con los medios y recursos inherentes; LVI - son inadmisibles, en el proceso, las pruebas obtenidas por medios ilícitos; [...] LXVIII - se concede siempre el habeas corpus en el caso de que alguien sufra o se vea amenazado de sufrir violencia o coacción en su libertad de locomoción, por ilegalidad o abuso de poder; LXIX - se concede el mandato de seguridad para proteger el derecho líquido y cierto, no amparado por el habeas corpus o habeas data, cuando el responsable por la ilegalidad o abuso de poder sea la autoridad pública o el agente de la persona jurídica en el ejercicio de atribuciones del poder Público; [...] LXXI - se concede el mandado de requerimiento siempre que la falta de la norma reglamentaria haga inviable el ejercicio de los derechos y libertades constitucionales y de las prerrogativas inherentes a la nacionalidad, a la soberanía y a la ciudadanía; LXXII - se concede el habeas data: a) para garantizar el conocimiento de las informaciones relativas a la persona del solicitante, constantes de registros o bancos de datos de entidades gubernamentales o de carácter público; b) para la rectificación de los datos, cuando no se prefiera hacerlo por proceso sigiloso, judicial o administrativo; LXXIII - cualquier ciudadano es parte legítima para proponer cualquier acción popular destinada a anular un acto lesivo al patrimonio público o de cualquier entidad en la que el Estado participe, a la moralidad administrativa, al medio ambiente y al patrimonio histórico y cultural, quedando el autor, salvo una comprobada 
tratamiento destinado a los Derechos Fundamentales de naturaleza individual y colectiva, siendo un verdadero portal de la constitucionalización de los diversos derechos privados y públicos del ordenamiento brasileño.

Como se observa por la simple lectura de los incisos del art. $5^{\circ}$, CRFB, aunque con el filtro de la citación a favor de la utilización de la misma metodología utilizada con la CE, la Constitución brasileña contiene una extensa lista de disposiciones que se diluyen en el ámbito del derecho material y procesal y están, en su mayor parte, reiterados en los textos de la legislación infraconstitucional, en constante modificación desde las décadas siguientes al nuevo orden constitucional al finales de 1980.

Asimismo, tanto en el ámbito de la CE como de la CRFB, el derecho de acceso a jueces y tribunales es un derecho fundamental, estrictamente relacionado con el derecho de acción y con la actuación de la jurisdicción. Y todo eso se produce en el ámbito de los procesos judiciales. También es el lado opuesto de la prohibición de la autotutela ${ }^{16}$ por parte de quien se entiende que es titular de derechos y trata de prevenir o remediar sus intereses con la participación de jueces y tribunales, lo que supone para el Estado una gran responsabilidad, puesto que es el garante y debe, bajo pena de incurrir en mora con respecto a la sociedad si no proporciona este derecho fundamental positivo.

\subsection{Posiciones doctrinales en España}

En la doctrina de MORENO CATENA encontramos la idea de que, en ambos casos, el mandamiento del derecho fundamental pretende proteger, en su totalidad, los diversos momentos del ejercicio del derecho de acción por parte de los que se considera que son titulares de las posiciones jurídicas activa y pasiva en situaciones concretas del derecho material. El autor también aprovecha para diferenciarlo del simple acceso (formal e inicial) a los jueces y tribunales, así como de cualquier alusión al derecho a una sentencia de mérito, lo que llevaría la adopción de la teoría de la acción en su sentido concreto. ${ }^{17}$

mala-fe, exentado de gastos judiciales y de la carga de los costes legales; LXXIV - el Estado prestará asistencia jurídica integral y gratuita a los que comprueben insuficiencia de recursos; LXXV - el Estado indemnizará al condenado por error judicial, así como lo que queda prendido además del tiempo fijado en la sentencia;[...] LXXVII - son gratuitas las acciones de habeas corpus y habeas data y, en la forma de la ley, los actos necesarios para el ejercicio de la ciudadanía. (Reglamento) LXXVIII a todos, en el ámbito judicial y administrativo, se les asegura la razonable duración del proceso y los medios que garanticen la celeridad de su tramitación. (Incluido por la Enmienda Constitucional no 45, de 2004).

${ }^{16}$ MORENO CATENA, V., CORTÉS DOMINGUES V., Introducción al Derecho Procesal, Ed. Tirant lo Blanch Valencia, , 2004, p. 219.

17 "El derecho a obtener la tutela efectiva de los jueces y tribunales - que representa el parámetro normativo a utilizar- se salvaguarda, como veremos, con la obtención de una resolución judicial, favorable o no al actor, que habrá de recaer sobre el fondo sólo concurren los presupuestos procesales para ello, extendiéndose a su efectivo cumplimiento, según acertada y reiterada doctrina del Tribunal Constitucional. Se trata, por tanto, de un derecho fundamental - con la inherente tutela privilegiada que la propia Constitución le otorga - de ámbito más restringido que el derecho a una sentencia favorable (teoría concreta), pero de contenido más amplio que el derecho de simple acceso a los tribunales, que resulta, naturalmente, implícito en el concepto enunciado.”(Ibídem, p. 219). 
TAPIA FERNÁNDEZ también sostiene la misma posición. A pesar de que señala el alto volumen de decisiones del Tribunal Constitucional sobre el tema, apunta en su obra algunas sentencias que acabaron por afirmar una posición de referencia para las décadas siguientes acerca de lo que se debe entender por tutela judicial efectiva. ${ }^{18}$

Por otra parte, acerca de la posible interpretación de que el derecho a la tutela judicial efectiva daría lugar a una necesaria acepción de la acción por su sentido concreto, el Tribunal Constitucional ya se pronunció en la STC 22/1982, a favor de la visión abstracta de la acción, quedando claro que una decisión de fondo, y también más favorable, dependerá obviamente de cada caso en el proceso judicial. ${ }^{19}$ Además de este juicio, también es posible observar, de acuerdo con la catedrática de Derecho Procesal de la UIB, que el TC se manifestó en los años y década siguiente con el mismo concepto, en los términos de laso, de 21 de enero; 65/1988, de 21 de marzo; , entre otros, ${ }^{20}$ consolidando una importante posición jurisprudencial, ciertamente influyendo no sólo en los juicios futuros en el mismo ámbito de cuestionamientos, sino generando la base para el desarrollo de la expansión de los distintos contenidos de la tutela judicial efectiva.

ORTELLIS RAMOS, por su vez y con una propuesta más amplia, se ocupa del derecho fundamental a la tutela judicial efectiva, abordando no sólo el art. 24.1 CE sino otras varias disposiciones que también se ocupan del derecho de acción, de los cuales el autor pone de relieve los arts. 53.2 CE, $124 \mathrm{CE}$; 161.2; $162 \mathrm{CE}$ y $125 \mathrm{CE}$, cada uno con su propia especialidad, invariablemente ligados a la ampliación o restricción de ejercicio, incluyendo los medios de tutela disponibles para ello. ${ }^{21} \mathrm{El}$ autor finaliza el enfoque conceptual del derecho de acción con

18 "El derecho a la tutela judicial efectiva, reconocido por las diversas Constituciones modernas, se concretiza como derecho fundamental (y por lo tanto, protegido por la garantía reforzada de recurso de amparo ante el Tribunal Constitucional, en caso de ser vulnerado) en el art. 24.1: "Todas las personas tienen derecho a obtener la tutela efectiva de los jueces y tribunales en el ejercicio de sus derechos e intereses legítimos, sin que, en ningún caso, pueda producirse indefensión". El contenido concreto de este derecho a la tutela efectiva ha venido delimitado por la abundantísima jurisprudencia emanada del Tribunal Constitucional, que por un lado, lo ha desvinculado del tradicional derecho de acción (que se estudiará en la siguiente pregunta): y, por otro, lo ha utilizado como comodín para fundamentar en él un compendio de garantías constitucionales no expresamente previstas en el apartado segundo de este art. 24 (como se ha estudiado en lección quinta). El Tribunal Constitucional, desde sus primeras sentencias, ha venido manifestando que "el art. 24 supone, no solo que todas las personas tienen derecho al acceso a los tribunales para el ejercicio de sus derechos e intereses legítimos, sino también que dichas personas - todas las personas - tienen derecho a obtener una tutela efectiva de dichos tribunales sin que como se dice textualmente en el referido artículo, en ningún caso pueda producirse indefensión... La tutela efectiva supone que los recurrentes sean oídos y tengan derecho a una decisión, fundada en Derecho, ya sea favorable o adversa, y también que la igualdad entre las partes propias de todo el proceso en que éstas existan, sea asegurada de forma que no se produzca desigualdad entre las mismas y consiguiente indefensión" (S.T.C. 13/1981, de 22 de abril)". (TÁPIA FERNÁNDEZ, I., Lecciones de Derecho Procesal, Ed. Palma, 2002, pp.93-94.)

${ }^{19}$ STC 22/1982.

${ }^{20}$ TÁPIA FERNÁNDEZ, I, op. cit, p. 94.

21 "El autor trata de lo que llama "Preceptos Constitucionales Referentes a la Acción" de la siguiente forma: En la Constitución española se encuentran diversos preceptos que versan sobre materias propias de la acción, aunque el ámbito normativo de los mismos tiene una diferente extensión.1o) El art. 53.2CE contempla el derecho de acción dirigido a recabar la tutela de los derechos y libertades fundamentales reconocidos en el art. 14 y la Sección 1a del Capítulo segundo CE. 2o) El art. 124.1 CE enuncia las funciones del Ministerio Fiscal, entre las que destaca la de promover la acción de la justicia respecto a determinados objetos, es decir, provocar el ejercicio de la potestad jurisdiccional mediante el ejercicio de la acción en materias jurídicas determinadas. 3o) Los arts. 161.2 y 162 CE determinan quienes tienen derecho a provocar la actividad jurisdiccional de Tribunal Constitucional 
referencia del art. 24.1 CE, lo que confirma la posición adoptada aquí, como la parte invariablemente restante del ejercicio de la acción por parte de los titulares del derecho, por lo que en el análisis del mencionado contenido y, quizás de la Teoría General del Proceso, la Acción debería estar sobrepuesta a la Jurisdicción y Proceso.

Para MONTERO AROCA, el derecho a la jurisdicción y el derecho a la tutela judicial efectiva serían términos sinónimos, caracterizados en el art. 24.1 CE, junto con la Acción y el Proceso, institutos también importantes para que todo lo que esté constitucionalmente previsto se materialice. Es la percepción doctrinal más tradicional que ya se ha comentado anteriormente; parte de la Jurisdicción hacia la Acción y, por último, donde "todo" se produce, es decir, el Proceso.

El autor llega al final de su razonamiento sosteniendo que la Acción, "se enlaza así con los derechos de las partes en el proceso....", (texto completo más abajo), demostrando como la Acción tiene su concepto inicial bien definido, pero sus elementos o contenido ya se mezclan principalmente en medio de las características del Proceso.

En otra obra, MONTERO AROCA y FLORS MATÍES se ocupan del Recurso de Amparo, y presenta, en base a la SSTC 185/1987, de 18 de noviembre y 30/2003, de 13 de febrero, la posición del TC acerca de la tutela judicial efectiva. Merece que transcribamos el texto, por el singular ángulo de enfoque, destacando el vínculo que se establece entre los jueces y los legisladores:

\footnotetext{
"Se trata, según lo ha definido el propio Tribunal, de un derecho prestacional de configuración legal cuyo ejercicio y prestación están supeditados a la concurrencia de los presupuestos y requisitos que en cada caso haya establecido el legislador, que no puede, sin embargo, fijar obstáculos o trabas arbitrarios o caprichosos que impidan la tutela judicial garantizada constitucionalmente."22
}

específicamente. 4o) El art. 125 CE reconoce la acción popular en el proceso penal. Pero las posibles consecuencias de este reconocimiento constitucional están sometidas a una doble limitación; en primer término, la que deriva de la expresa remisión a una configuración legislativa aparentemente no sujeta a límites sustanciales ( en la forma y con respecto a aquellos procesos penales que la ley determine); en segundo lugar la no tutela de este derecho de acción mediante el amparo, salvo que, en algún caso pudiera entenderse que una violación del mismo supone también la del art. 14 o la de otro derecho de la Sección primera del Capítulo segundo CE. Ambas limitaciones se superarían en parte si pudiera concluirse que el art. 24.1 CE se refiere también a la acción penal. Esto lo admiten algunos autores, distinguiendo la posición del acusador popular (simple ciudadano) y del acusador particular (ofendido por el delito), y considerando la segunda incluida en el art. 24.1 CE. Otros autores lo rechazan porque las acciones de uno y otro acusado no son distintas y un ningún caso están destinadas a tutelar un interés personal. La jurisprudencia del Tribunal Constitucional se inclina decididamente por la primera postura. [...]. $7^{\circ}$ ) El precepto en el que se ha centrado la elaboración jurisprudencial y doctrinal de la acción como derecho fundamental es el del art. 241. CE, según el cual todas las personas tienen derecho a obtener la tutela efectiva de los jueces y tribunales en el ejercicio de sus derechos e intereses legítimos, sin que en ningún caso pueda producirse indefensión. Es comprensible la primacía atribuida a este precepto, primero por ser el de ámbito más general y segundo, porque el derecho que reconoce es de los tutelables mediante el recurso de amparo". (ORTELLS RAMOS, M, en ORTELLS RAMOS, M, CÁMARA RUIZ J, JUAN SANCHÉS, R., op cit, pp.203-204.) ${ }^{22}$ MONTERO AROCA, J., FLORS MATÍES, J., Amparo Constitucional y Proceso Civil, Ed. Tirant Lo Blanch Valencia, , 2008, p. 62. 
Posteriormente, los autores presentan su propio concepto sobre la tutela judicial efectiva, señalando, al final, una preocupación acerca del principio del contradictorio visto por el legislador y el derecho de defensa, propiamente por ser respetado o violado en un proceso real, ${ }^{23}$ presentando en una nota de pie de página, el repertorio doctrinal sobre el tema. ${ }^{24}$

\title{
3.2. Posiciones doctrinales en Brasil
}

En el ámbito doctrinal brasileño existe también una extensa capilaridad sobre el reconocimiento del derecho a la tutela judicial efectiva, aunque con el predominio del uso de la expresión "acceso a la justicia", como ya se ha señalado anteriormente. Tanto en el ámbito de la doctrina constitucional, como en el ámbito del Derecho Procesal Civil, principalmente tras la CRFB de 1988, se observa el reconocimiento del derecho constitucional de acceso a los jueces y tribunales como un derecho fundamental, pero existe, del mismo modo que se encontraron en la doctrina desarrollada en España, diferentes formas de aproximación al tema. Como también en la percepción de semejanza del orden de Jurisdicción, Acción y Proceso en el ámbito de los manuales de derecho procesal civil patrio.

A modo de introducción, la doctrina de LEONARDO GRECO, trae la percepción del acceso a la Justicia como un verdadero derecho fundamental, necesario, imprescindible para la implementación de una serie de otros derechos y que no puede obstaculizarse por cuestiones secundarias, ante su magnitud constitucional:

\begin{abstract}
"El acceso a la Justicia, como derecho fundamental, corresponde al derecho que cada ciudadano tiene individualmente al ejercicio de la función jurisdiccional sobre cierta pretensión de derecho material, sobre el mérito de su pedido. Este derecho no puede fracasar por obstáculos irrazonables, con el pretexto de falta de condiciones de la acción o de supuestos procesales, [...]".25
\end{abstract}

\footnotetext{
${ }^{23}$ El concepto de los autores y los comentarios finales con respecto a la posición del TC: "La tutela judicial efectiva se concreta en el derecho que tienen todas las personas al acceso a los órganos jurisdiccionales con arreglo a las normas de procedimiento legalmente establecidas y a obtener de ellos una respuesta motivada y de fondo, dotada de invariabilidad, y a la ejecución de lo resuelto. La tutela judicial efectiva se conecta a veces con la interdicción de la indefensión, a la que también se refiere el artículo 24.1 de la CE, aunque el concepto de indefensión no se maneja siempre con el mismo sentido, como veremos en el epígrafe siguiente. En cualquier caso muy en general significa que la tutela judicial habrá de procurarse de modo tal que garantice a todas las partes de un proceso concreto las posibilidades de defender efectivamente sus derechos e intereses legítimos. Posiblemente la sentencia anterior hubiese sido más clara en su exposición si hubiera distinguido entre:1 ) Principio de contradicción que obliga al legislador ordinario a la hora de regular el proceso, de modo que su desconocimiento lleva a la inconstitucionalidad de la ley, y 2) Derecho defensa, que es el que puede ser violado en un proceso concreto.'(Ibídem, pp.64-65).

${ }^{24}$ Con respecto a la doctrina se citan los siguientes autores: "GONZÁLES PÉREZ, El derecho a la tutela judicial efectiva, $2^{a}$ edición, Madrid, 1989; FIGUERUELO BURRIEZA, El derecho a la tutela judicial efectiva, Madrid, 1990; ALONSO GARCÍA, "El art. 24.1 de la CE en la jurisprudencia del TC: problemas generales y acceso a los tribunales", en: Estudios sobre la Constitución española. Homenaje al profesor E. García de Enterría, II, Madrid, 1991; CHAMORRO BERNAL, La tutela judicial efectiva (Derechos y garantías procesales derivados del art. 24 de la Constitución), Barcelona, 1994; y CORDÓN MORENO, "El derecho a obtener la tutela judicial efectiva", en: Derechos procesales fundamentales, CGPJ, Manuales de Formación Continuada, 22 Madrid, 2005, pp. 213243.

${ }^{25}$ GRECO, L., in MESSIAS PEIXINHO, M., FRANCO GUERRA, I., NASCIMENTO FILHO, F. Os Princípios da Constituição de 1988. 2a ed., Rio de Janeiro, Lumen Iuris, 2006, p. 372.
} 
En este artículo, el procesalista brasileño, también autor de diversas otras obras, mediante un detallado análisis explica el contenido de la tutela judicial efectiva.

NASCIMENTO FILHO, otro ilustre jurista patrio, sostiene la relevancia del principio constitucional de acceso a la justicia contemplado el art. 5 $\mathrm{XXXV}$, y aporta una posición complementaria, ante la ausencia en Brasil de un Jurisdicción Contenciosa en el ámbito administrativo. ${ }^{26}$

\section{CICHOKI NETO, en relación a la temática del acceso a la Justicia en las Constituciones} de Brasil, menciona la historicidad sobre las cartas anteriores que con la carta de 1946 el principio fue insertado en sede constitucional como una amplitud y seguridad bastante menor a la que hoy día existe en la CRFB, en su art. $5^{\circ}, \mathrm{XXXV},{ }^{27}$ sin perjuicio de las demás disposiciones que van a apuntar a la secuencia de ítems o contenido de la tutela judicial efectiva.

El autor también aborda la temática del acceso a la Justicia en otras Constituciones de países de la common law y civil law, incluyendo la Constitución española de 1978, ratificando lo que inicialmente ya se vio acerca de la percepción garantista desde el punto de vista material

\footnotetext{
26 "La Constitución hoy en día se expresa cuando determina que ninguna lesión o amenaza de lesión puede ser apartada del control por parte del poder Judicial. En Brasil, tal garantía ha adquirido relevancia en la medida en que no se admite el Contencioso Administrativo, que traslada a órganos separados de la estructura del poder Judicial el conocimiento y juicio de las disputas que interesan al Estado como parte implicada. Explica el "Mestre" de Lisboa, Jorge Miranda, que sólo quien tenga conciencia de sus derechos puede tener conciencia de las ventajas y de los bienes que puede disfrutar en su ejercicio o realización [...]. En la concepción del profesor de Coímbra la protección de acceso al Poder Judicial es un derecho a la defensa del particular ante los poderes públicos, ya sea contra los actos administrativos o en contra de los actos de particulares. Vinculado a los derechos fundamentales el acceso a la Justicia forma un "núcleo esencial de la garantía institucional de la vía judicial, traduciéndose en la monopolización de la coacción física legítima, en el deber de mantenimiento de la paz jurídica y en la prohibición de autodefensa. Uno de los objetivos de la Jurisdicción es preservar la paz social. El acceso debe ser efectivo y material, lo que significa decir que la respuesta presentada por el Estado debe dirimir el conflicto existente o legitimar la situación ofrecida, en un plazo razonable. Tal concepción, sin embargo, no aleja la necesidad de cumplimentar ciertos presupuestos pertinentes al ejercicio del derecho de acción y a la formación del proceso. La garantía del acceso al Poder Judicial está íntimamente relacionada con la comprensión del principio del due process of law, traducido por el constitucionalista portugués Canotilho, como un proceso justo establecido para privar a alguien de la vida, libertad o propiedad. (NASCIMENTO FILHO, F., en MESSIAS PEIXINHO, M., FRANCO GUERRA, I., NASCIMENTO FILHO, F. Os Princípios da Constituição de 1988. , Ed. Lumen Iuris, Rio de Janeiro, 2006, pp. 353-353.

${ }^{27}$ Sobre el Constitucionalismo brasileño, el principio del acceso a la Justicia ("La Constitución del Imperio de 1824, la primera Constitución republicana de 1891, y las Constituciones de 1934 y de 1937, no hicieron ninguna referencia al principio de "inafastabilidade" (derecho de acción) del control jurisdiccional aunque, según algunos autores, el mecanismo de la tripartición de los poderes la haría implícita. Sólo con la Constitución de 1946 (art. $141, \S 4^{\circ}$ ), este principio se contempló en el ordenamiento: "la ley no podrá excluir de la apreciación del poder Judicial cualquier lesión de derecho individual”. Sin embargo, el Acto Institucional n.2, de 27 de octubre de 1965, limitó en gran medida la función jurisdiccional, al excluir de la apreciación del poder Judicial los actos practicados por el Comando de la Revolución de 1964 por parte del Gobierno Federal, realizados con fundamento en el Acto Institucional N. 9 de 9 de abril de 1964, en este mismo acto y en sus complementos y, también, en las Resoluciones de las Asambleas Legislativas y del Concejo, a través de los cuales se hubieran revocado los mandatos electivos de gobernadores, diputados, alcaldes y concejales, a partir de 31/03/64 (art. 19). A su vez, las Constituciones de 1967 (art. 150, $\S 4^{\circ}$ ) y la Referencia Constitucional n. 1 (Art. 153, $\S 4^{\circ}$ ) ratificaron el mismo principio contenido en la Carta de 1946. Por último, el Acto Inconstitucional N. 5, de 13/12/68, - art. 11-, eximió "de cualquier apreciación judicial todos los actos practicados de acuerdo con este Acto Institucional y sus Actos Complementarios, así como los respectivos efectos, "suspendiendo también las garantías constitucionales de los magistrados" (CICHOKI NETO, op. cit, pp. 92-93).
} 
y formal de la aquí apuntada, "tutela judicial efectiva", incluso con referencia a importantes decisiones del Tribunal Constitucional sobre el no agotamiento del tema con el mero acceso a los tribunales, es decir, no basta que no haya el ejercicio de la acción y su admisibilidad, es preciso también que el derecho de acción continúe en el ámbito del debido proceso legal (STC 117/1986; 47/1987; STC 105/1989).

Se trata, a ejemplo de lo que se observa en la doctrina española, de un imprescindible fundamento del Estado de Derecho, especialmente en los Estados Democráticos de Derecho, donde la necesidad contemporánea de la participación y legitimación del ciudadano en el poder del Estado es cada vez más real, entendida aquí no sólo en su aspecto formal, sino principalmente material.

Esta es una realidad que sigue constante en el Capítulo III de la presente investigación; es decir, como enfoque de los institutos ligados al ejercicio en la Acción, en el ámbito del estudio relativo al proceso, reforzando la percepción doctrinal acerca de la trilogía estructural del Derecho Procesal Civil ya citada, en este orden, de la Jurisdicción, la Acción y el Proceso, aunque no sea en el orden que aquí venimos sosteniendo, en orden a una mejor efectividad de la actuación jurisdiccional de nuestros jueces y tribunales. En este sentido, encontramos en GUASP una posición aclaradora, valorizando los actos de las partes e del juez en ámbito la naturaleza del proceso. ${ }^{28}$

La acción, aunque tratada como algo no puntual, relacionada sólo con la mera provocación de la jurisdicción, ${ }^{29}$ a menudo se ha separado de su concepto, de los elementos que caracterizan su actuación en el ámbito procesal y procedimental. Para muchos autores, son contenidos del Proceso y no de la Acción, con un sentido increíble de apropiación, ${ }^{30}$ que según nuestra investigación, explica en alguna medida el porqué del enfoque del estudio del Proceso y de sus posibles ritos. Al final, son los actos procesales los que permiten, como si ellos no fueran actos del ejercicio de regular la acción a favor de la tutela judicial efectiva.

\section{ALGUNAS POSICIONES DOCTRINALES CONCLUDENTES}

ORMAZABAL SÁNCHEZ ya parte de un referencial más próximo a lo que se viene sosteniendo en este Capítulo III, sobre la necesidad de tener en la Acción, y por la Acción, el referencial teórico jurídico inicial para la valoración que debe garantizarse en nombre del art. 24.1 CE. ${ }^{31}$ Se trata de un enfoque que se entiende con poco más de coherencia, ya que sin

\footnotetext{
${ }^{28}$ GUASP, J., Concepto y Metodo del Derecho Procesal, Ed. Civitas, Madrid, 1997, pp. 32-33.

${ }^{29} \mathrm{Vid}$. nota 14.

${ }^{30}$ GUASP. J., ARAGONESES, P. Derecho Procesal Civil. Tomo. 1. Introducción, parte general y procesos declarativos ordinarios. Madrid, 2003, pp. 237-238.

${ }^{31} \mathrm{El}$ autor, mediante el análisis de las teorías de la acción y, más específicamente, de cuál de estas teorías estaría materializada en el ámbito del art. 24.1 y de acuerdo con su propia redacción y, también, en base a las sentencias del TC, presenta su visión sobre el derecho a la tutela judicial efectiva: "La conclusión que acabamos de exponer, es decir, que el alcance del derecho consagrado por el art. 24.1 CE consiste en el derecho a obtener una resolución sobre el fondo, que resuelva favorable o desfavorablemente sobre las pretensiones deducidas por los justiciables, 
Acción no hay actuación primaria en nombre de la Jurisdicción y del Proceso. Y, si no hay Acción, no hay actuación de la Jurisdicción y, mucho menos Proceso.

PÉREZ GIl, en trabajo académico presentado en la Facultad de Derecho de la Universidad de Burgos, al referirse al derecho a la tutela judicial efectiva previsto en el art. 24.1 $\mathrm{CE}$, parte de forma certera del concepto, de las teorías y de la naturaleza de la Acción para buscar la propia comprensión del texto constitucional, en un texto que merece destacar, ante la conexión de las ideas encontradas y defendidas en la presente investigación.

Según se observa, el autor, destaca claramente la conexión que aquí se aboga entre la Acción (y necesaria concepción) y el derecho a la tutela judicial efectiva prevista en el art. 24.1 CE. Mediante el ejercicio de la acción la "rueda de la Justicia dictada por jueces y tribunales comienza a moverse y, todo lo que se quiera garantizar a partir del sentido del art. 24.1 CE, debe, en una mejor interpretación, considerarse como referencial primario, aunque con los consecuentes añadidos de la actuación de la Jurisdicción.

Con relación al Proceso, se pide licencia al discurso académico, para posicionarse en el sentido de que se comete la misma equivocación de origen, pero en mayor escala, puesto que, en cuanto entorno de manifestaciones de titulares de derecho, procuradores, abogados fiscales y jueces en las fases de conocimiento y ejecución, es totalmente dependiente de la Acción y Jurisdicción como demuestra la titularidad de derechos al Proceso. Es un medio y no un fin en sí mismo, debiendo estar orientado, regulado, interpretado y decidido con el mandato constitucional del ejercicio de la acción como plenitud del cumplimiento del art. 24.1. ${ }^{32}$

Tal es la convicción de PÉREZ GIL sobre la referencia teórica de la acción en base al art. 24.1 CE que, tras atravesar metodológicamente las discusiones acerca del carácter concreto o abstracto de la acción afirma su posición claramente abstractivista ${ }^{33}$. Acaba abogando por el derecho a la tutela judicial y su naturaleza como derecho fundamental, no sólo en el ámbito

ha sido afirmada y confirmada por el TC con una copiosísima cantidad de resoluciones, en las cuales el Tribunal ha detallado los contornos y características de este derecho fundamental ( a modo de ejemplo y para no comenzar una enumeración interminable, pueden consultar-se las SSTC 55/1987 y 131/1990) ”. ORMAZABAL SÁNCHEZ, G., op. cit, p. 119.

${ }^{32}$ Es el sentido expresado según Pietro Calamandrei y Jayme Guasp Delgado cuando se refieren a la conceptuación de la acción, como sostiene Julio Pérez Gil: ("227 CALAMANDREI, P. Istituzioni di Diritto Processuale Civile, p. 115). También en el sentido expuesto supra, vid GUASP DELGADO, J., La pretensión procesal, cit, p. 52: la acción seria un puro poder político o administrativo, previo al proceso y a mundo procesal) (PEREZ GIL, J. Op.cit, p. 59).

33 “Como se ha advertido anteriormente, es común entre la doctrina procesal partir hoy de un concepto abstracto de la acción, en cuanto derecho a la actividad estatal de impartir justicia a través de los órganos jurisdiccionales y en la forma jurídicamente regulada. En este sentido, se sitúan los criterios de una serie autores que asumen la constitucionalización de la acción en sentido abstracto en el art. 24.1 CE, aun cuando su defectuosa reacción pudiera inducir a la opción contraria. Cabe así citar, entre otros muchos y con las debidas matizaciones a ALMARGO NOSETE, MONTERO AROCA, GIMENO SENDRA, MORENO CATENA O PEDRAZ PENALVA. También nosotros, y en los términos que se expondrán, nos adscribimos a esta corriente de opinión en tanto estimamos que es la más adecuada para dar respuesta constitucional a la verdadera naturaleza y función de la acción" (Ibídem, pp.59-60). 
constitucional interno, sino también en el ámbito supranacional, cuando cita las diversas normas orientadoras en un general sentido y con pretensiones de superar fronteras, literalmente.

Así, a un modo de conclusión primaria, es un hecho, casi notorio, que la problemática mayor de la tutela judicial efectiva no gira en torno a las grandes discrepancias con respecto a su conceptuación, su reconocimiento jurídico como el derecho fundamental constitucional, o incluso lo que se debe esperar de su realización. En este punto, el análisis de los autores analizados, citados y tantos otros mencionados, queda claro que existe una uniformidad ante la tutela judicial efectiva, sin perjuicio de algunas divergencias doctrinales ya contestadas por el TC con respecto a la aptitud de las teorías concreta y abstracta de la acción y correspondiente sintonía con el artículo. 24.1 CE y con el artículo 5º XXXV CRFB 88.

\section{REFERENCIAS}

AlCAla ZAMORA Y CASTILlo, N. Proceso, Autocomposición y Autodefensa, México, 1991.

CICHOCKI NETO, J. Limitações ao Acesso à Justiça, Ed. Juruá, Rio de janeiro, 2009.

CAPPELLETTI, M. e GARTH, B. Acesso à justiça, trad. E. G. Northfleet., Ed. Sergio Antonio Fabris, Porto Alegre, 1998.

GRECO, L., in MESSIAS PEIXINHO, M., FRANCO GUERRA, I., NASCIMENTO FILHO, F. Os Princípios da Constituição de 1988. 2a ed., Rio de Janeiro, Lumen Iuris, 2006.

GUASP, J., Concepto y Metodo del Derecho Procesal, Ed. Civitas, Madrid, 1997.

GUASP. J., ARAGONESES, P. Derecho Procesal Civil. Tomo. 1. Introducción, parte general y procesos declarativos ordinarios. Madrid, 2003.

MONTERO AROCA, J., Introducción al Derecho Procesal, Ed. Tecnos, Madrid, 1976.

MONTERO AROCA, J., FLORS MATÍES, J., Amparo Constitucional y Proceso Civil, Ed. Tirant Lo Blanch Valencia, 2008.

MORENO CATENA, V., CORTÉS DOMINGUES V., Introducción al Derecho Procesal, Ed. Tirant lo Blanch Valencia, 2004.

NASCIMENTO FILHO, F., en MESSIAS PEIXINHO, M., FRANCO GUERRA, I., NASCIMENTO FILHO, F. Os Princípios da Constituição de 1988. , Ed. Lumen Iuris, Rio de Janeiro, 2006.

ORMAZABAL SANCHÉZ, G., Introducción al Derecho procesal, Ed., Marcial Pons Madrid, 2007.

ORTELlS RAMOS, M., CAMARA RUIZ, J., JUAN SANCHÉZ, R., Derecho Procesal. Introduction, Ed. Tirant Lo Blanch,Valência, 2003. 
PEDRAZ PENAlVA, E. Derecho Procesal Penal. Tomo I. Principios de Derecho Procesal Penal, Ed. Colex, Madrid, 2000.

TÁPIA FERNÁNDEZ, I., Lecciones de Derecho Procesal, Ed. Palma, 2002. 